\title{
ПРОБЛЕМА КРИЗИСА ИДЕНТИЧНОСТИ В УСЛОВИЯХ ГЛОБАЛИЗАЦИИ
}

\author{
(C) 2019 Фадеева Инна Авенировна \\ кандидат экономических наук, доцент \\ Дипломатическая академия Министерства иностранных дел Российской Федерации \\ 119021, г. Москва, ул. Остоженка, д.53/2, стр. 1 \\ E-mail: innaf576@mail.ru
}

Одной из основных причин, по которой процессы глобализации воспринимаются как негативные, является «растворение» идентичности стран. Действительно, такая проблема имеет место быть и требует научного осмысления. В науке выделяются различные причины и последствия наблюдающейся проблемы кризиса идентичности. К таковым в исследовании отнесены социальные, культурные, экономические, институциональные, политические, правовые. Формирование идентичности процесс весьма сложный и неоднозначный, особенно когда он рассматривается в отношении крупных интеграционных структур, к примеру, когда идет речь о «европейской идентичности». Целью исследования является осмысление феномена кризиса идентичности в условиях глобализации на примере европейской интеграции. В исследовании проводится обзор теоретических подходов к определению понятия «идентичность». Обосновываются факторы, опосредующие возникновение дискурса о кризисе идентичности в условиях глобализации. Приводятся экономические детерминанты, ускорившие развитие проблемы кризиса идентичности в странах ЕС в условиях глобализации. Проблемы кризиса идентичности на примере стран ЕС рассмотрены путем раскрытия иерархической структуры проявлений данной проблемы: международного, наднационального, локального и общественного уровней. Проведена связь и установлено возможное влияние проблем кризиса идентичности на протекание дезинтеграционных процессов в крупнейших региональных союзах.

Ключевые слова: идентичность, глобализация, кризис, ЕС, интеграция, дезинтеграционные процесcbl.

Глобализационные процессы вносят в геоэкономическую повестку рассмотрение проблем, которые окажут значительное влияние на развитие межгосударственных интеграций в средне- и долгосрочный периоды. Такой проблемой сегодня, в контексте дезинтеграционных процессов, наблюдающихся в различных регионах мира и интеграционных структурах, является проблема кризиса идентичности. Проблема кризиса идентичности особенно ярко проявляется в странах ЕС - интеграционной структуры, справедливо рассматриваемой научным сообществом в качестве уникального примера и модели институционально оформленного объединения стран различного уровня экономического развития, отличающихся социально-культурных условий, политических различий. В условиях взаимонаправленных процессов - с одной стороны, устремлений наднациональных органов ЕС усилить процессы интеграции, минимизировать центробежные тенденции, создать новые механизмы политического влияния на страны-участницы и, с другой стороны, усиливающееся недовольство национальных правительств особенно стран, отличающихся уровнем экономического развития, их стремление повысить свой экономический и политический суверенитет,- исследование проблемы кризиса идентичности, её генезиса, сущности, возможных проявлений в будущем, будет иметь как теоретическое, так и прикладное значение.

Некоторые аспекты наблюдающегося сегодня кризиса идентичности исследованы в работах авторов, представляющих не только экономическое, но и другие научные направления: «число научных публикаций по данной тематике исчисляется на сегодняшний день сотнями» [1, с.10]. Обуславливается это тем, что проблема кризиса идентичности является многоаспектной - для этой проблемы в равной степени значимы экономические, социологические, политические детерминанты, их философское осмысление. Таким образом, данная проблема рассматривается в публикациях авторов экономического, политологического, социологического, философского областей знаний.

Идентичность на страновом уровне определяют различными способами. И.С. Семенеко на- 
зывает идентичность цивилизационным самостоянием народов [1, с.8]. В измерении отдельных представителей социологической науки кризис государственной идентичности отождествляется с процессом глобализации [2]. Идентичность также рассматривают как то, что определяет действия субъекта (индивида, государства, наднационального объединения) [3]. Под идентичностью С.В. Арапина понимает совокупность характеристик, отличающих жителей одних стран и регионов от других - в традициях, культуре, образе жизни, системе мышления [4]. Лаконичное определение идентичности дано С.Хантингтоном, определяющим данное понятие как «смысл себя» [5].

В данном исследовании понятие «идентичность» будет рассматриваться на двух уровнях: национальном и наднациональном. Под национальной идентичностью будет пониматься такая совокупность социально-культурных, исторических, политических и иных характеристик, которая позволяет населению страны самоидентифицровать себя по отношению к населению других стран и регионов. Под наднациональной идентичностью (на примере европейской) понимается собирательная, межгосударственная самоидентификация народов, населяющих территорию интеграционной структуры. Изучение современной проблемы кризиса идентичности целесообразно предварить уточнением основных подходов к формированию идентичности. Выделяются два подхода к изучению европейской идентичности: а) формирование идентичности «сверху»[6], где делаются акценты на общем наследии; б) формирование идентичности «снизу» - здесь используются социологические подходы для измерения реального количества и доли «приверженцев» европейской идентичности [7].

Проблемам кризиса идентичности как на национальном, так и над национальном уровнях посвящены исследования российских и зарубежных авторов. Многообразие исследований не позволяет охватить в данной работе всех аспектов рассматриваемой проблемы, поэтому рассмотрим наиболее заслуживающие внимание вопросы выбранной проблематики.

В работе Л.К. Мамедовой и В.А. Федорцева основное внимание уделяется кризису региональной идентичности на примере ЕС, в частности, авторы отмечают, что кризис идентичности становится одной из основных причин центро- бежных тенденций и распространения евроскептицизма. Кроме того, авторы подчеркивают, что рост националистических настроений можно расценивать как попытку европейских политических элит «укрыться в привычных рамках национальных государств от вызовов, связанных с новыми экономическими, политическими и социальными условиями» [8]. Указанные авторы уделяют также внимание кризису европейской идентичности в основном в контексте более тесной интеграции Западной и Восточной Европы, рассматривая основные сферы различий между частями региона: политических, институциональных, культурных, экономических, социальных. Так, объясняя экономические расхождения, исследователи точкой отсчета таких расхождений называют период промышленной революции, от которой страны Восточной Европы остались в стороне. Одной из основных угроз современной европейской идентичности справедливо называется неконтролируемая странами Европы (в особенности Восточной и Южной, которые становятся транзитными пунктами мигрантов) проблема иммиграции. Можем согласиться с тем, что недостаток факторов, которые могут быть положены в основу идентичности европейской интеграции в последние годы усиливается и может сыграть важную роль в дальнейшем в дезинтеграционных процессах Европейского региона.

Более глубокое осмысление предпосылок и причин кризиса идентичности на примере стран Европы приведено в публикации Е.В.Шишкиной, Е.В. Викторовой и О.В. Алексеевой, которые выделяют следующие факторы, затрудняющие дальнейшее развитие идентичности в рассматриваемом регионе [9]:

- отсутствие в общественном мнении единства в понимании понятия «европейская идентичность», что затрудняет выбор мер в её развитии;

- снижение влияния религиозного фактора на общественное развитие;

- языковая разобщенность стран ЕС, что влияет на политическое устройство и формирование правовой базы (законы парламента публикуются на всех официальных языках ЕС);

- расширение ЕС и усложнение культуры союза, что осложняет формирование идентичности;

- продолжающийся процесс политической интеграции ЕС, осложняющий формирование 
единого политического устройства;

- усиление процессов формирования регионального самосознания;

- миграционные потоки из развивающихся стран, что осложняет ситуацию в регионе.

Проблемы кризиса идентичности как в мире, так и в отдельных наиболее характерных с точки зрения его влияния на развитие интеграционных структур регионах, стали особенно заметны в период мировых кризисов. Мировые экономические кризисы показали сколь сильно глобализационные процессы усиливают взаимосвязь экономик мира, а негативные продолжающиеся изменения опосредуют «эффект домино», когда проблемы в одних странах непременно приводят к отрицательным последствиям в других. Уже в 2012 г. европейские исследователи обращают внимание на степень проникновения глобализации в экономическое развитие ЕС [10].

Кризис 2008-2009 гг. стал причиной пересмотра взглядов в различных регионах мира на вопросы идентичности. Так, сохранение валютного союза ЕС потребовало реализации мер, оказавших неравномерное влияние на экономику интеграционной структуры. Несбалансированность экономического воздействия наднациональных структур проявилась в увеличении нагрузки на бюджеты развитых стран для выравнивания экономического развития стран, находившихся в глубоком кризисе (Греция, Португалия, Ирландия). Такая политика несправедливого, по мнению национальных элит и общественности, распределения средств, вызвала критику наднациональных структур управления ЕС и повлияла на вопросы европейской идентичности. В частности, проблемы идентичности проявились на нескольких уровнях:

1. Международном уровне - страны-партнеры ЕС начинают пересматривать своё отношение к вопросам взаимодействия с интеграционной структурой, изменяется восприятие ЕС как одного из ведущих участников мировой системы экономических отношений. Уже в начале 2000-х гг. исследователи обращали внимание на возможность признания институциональной идентичности ЕС, которую следует рассматривать вне национальных идентичностей стран-участниц ЕС [11].

2. Наднациональном - на уровне управленческих структур ЕС кризис идентичности выражается в дистанцировании от продолжения реализации политики единой европейской идеи, расширения и укрепления единого европейского пространства.

3. Локальном (национальном) - противоречия на данном уровне, определяющие развитие дезинтеграционных процессов, имели место быть и ранее, усилившись в связи с воздействием внешних факторов (экономических, политических, социально-культурных). В политической повестке ряда стран стоит вопрос о выходе из ЕС, либо из стран, входящих в союз с созданием суверенного государства.

4. Общественном уровне - реализация несоответствующей уровням экономического развития стран ЕС финансовой политики стала причиной недовольства граждан развитых стран, возникают массовые настроения о целесообразности дальнейшего развития региона по пути формированию единой идентичности. В этом смысле характерны результаты социологического исследования «Евробарометр», согласно которым менее половины жителей Европы высказывают положительное отношение к ЕС, наблюдается снижение доверия к наднациональным структурам союза. Как отмечается в исследовании, негативные дезинтеграционные процессы в ЕС стали усиливаться с весны 2017 года: около $48 \%$ респондентов указали, что они скорее не доверяют руководству ЕС; более половины полагают, что их мнение не учитывается при принятии политических решений. Кроме этого, нет единства в отношении расширения интеграционной структуры: порядка $47 \%$ респондентов против принятия новых членов, $41 \%$ поддерживают такое направление развития ЕС [12].

Резюмируя, отметим, что проблема кризиса идентичности в современном мире, во многом ставшая результатом глобализационных процессов, многогранна и требует дальнейшего изучения. Несомненно влияние кризиса идентичности на дальнейшее развитие дезинтеграционных процессов в различных регионах и интеграционных структурах, в том числе ЕС. Наднациональная, «европейская идентичность», на наш взгляд, является конструктом искусственным и неустойчивым. Согласимся с исследователями, утверждающими, что европейская идентичность «представляет собой идейно-политическую конструкцию, рожденную в политических верхах Европы, но отнюдь не вызревшую на низовом, массовом уровне» [13].

Неустойчивость единой европейской иден- 
тичности особенно проявляется в условиях ния национальных правительств. На национальвлияния негативных внешних воздействий. ном же уровне говорить однозначно о наличии Исследования предсказуемо показывают, что региональной, наднациональной идентичности национальная идентичность, как в других ре- преждевременно. Проблема кризиса идентичгионах мира, так и в ЕС преобладает над над- ности пока не проявила себя в полной мере и в циональной. В современных условиях идея будущем будет оказывать влияние на протека«европейской идентичности» имеет скорее по- ние дезинтеграционных процессов в крупнейлитическую подоплеку - как способ объедине- ших интеграционных структурах.

\section{Библиографический список}

1. Семененко И.С. Потенциал европейской идентичности как ресурса политической интеграции (что показали выборы в Европарламент) // Человек. Сообщество. Управление. 2014. № 3.

2. Звоновский В.Б. Глобализация и кризис социокультурной идентичности // Вестник Омского университета. 2011. № 3 (61). С. 314-319.

3. Рычкова И.Ю. Влияние современных тенденций глобализации на европейскую идентичность в рамках Европейского союза // Научные труды Северо-Западного института управления. 2015. Т. 6. № 4 (21)., с. 332.

4. Арапина С.В. Европейская идентичность: теория и практика (некоторые аспекты) // Дневник АШПИ. 2013. № 29. C. 113-118.

5. Huntington S. Who are We? The Challenges to America's National Identity. N. Y.; L. Toronto; Sydney. 2004.

6. Bruter M. Political Identity and European elections. [Электронный ресурc]. URL - http://www.afsp.msh-paris.fr/ activite/diversafsp/collgspegael04/bruter.pdf (дата обращения 08.01.2019 г.)

7. Андросова Д.Н. Европейская идентичность и европейская интеграция. (обзор) // Актуальные проблемы Европы. 2010. № 2. С. 172-188.

8. Федорцев В.А., Мамедова Л.К. Европейский союз: поиск «европейской идентичности» // Проблемы национальной стратегии. 2011. № 4 (9). С. 44

9. Шиикина Е.В. Интеграционные процессы в ЕС и европейская идентичность: учебно-справочное пособие / Е.В. Шишкина, Е.В. Викторова, О.В. Алексеева. Санкт-Петербург. 2018. С. 43-44.

10. Берендеев М.В. Дискурс европейской идентичности в условиях кризиса в ЕС // Вестник Балтийского федерального университета им. И. Канта. Серия: Гуманитарные и общественные науки. 2012. № 12. С. 146-154.

11. Manners I., Whitman R. The "difference engine": Constructing and representing the international identity of the European Union //. Journal of European Public Policy. 2003. Vol. 10. № 3. P. 380-404.

12. Eurobarometer 2017 [Электронный ресурс] / European Parliament. URL - http://www.europarl.europa.eu/news/ en/headlines/priorities/eurobarometer-2017 (дата обращения 29.12.2018 г.)

13. Вайнштейн Г. Европейская идентичность. Возникающая реальность или фантом? [Электронный ресурс] / URL - http://politcom.ru/8315.html (дата обращения 08.01.2019 г.) 